\title{
Differential effects of sulforaphane in regulation of angiogenesis in a co-culture model of endothelial cells and pericytes
}

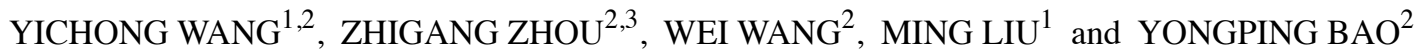 \\ ${ }^{1}$ The Fourth Affiliated Hospital, Harbin Medical University, Harbin, Heilongjiang 150001, P.R. China; \\ ${ }^{2}$ Norwich Medical School, University of East Anglia, Norwich, Norfolk NR4 7UQ, UK; ${ }^{3}$ Department of \\ Cardiovascular Disease, The Affiliated Hospital of Nantong University, Nantong, Jiangsu 226001, P.R. China
}

Received November 10, 2016; Accepted March 30, 2017

DOI: $10.3892 /$ or.2017.5565

\begin{abstract}
Aberrant neovascularization supports nutrients and the oxygen microenvironment in tumour growth, invasion and metastasis. Recapitulation of functional microvascular structures in vitro could provide a platform for the study of vascular conditions. Sulforaphane (SFN), an isothiocyanate, has been reported to possess chemopreventive properties. In the present study, the effects of SFN on cell proliferation and tubular formation have been investigated using endothelial cells (ECs) and pericytes in coculture. SFN showed a dosedependent inhibition on the growth of ECs and pericytes with $\mathrm{IC}_{50}$ values 46.7 and $32.4 \mu \mathrm{M}$, respectively. SFN (5-20 $\left.\mu \mathrm{M}\right)$ inhibited tube formation in a $3 \mathrm{D}$ coculture although a lower dose $(1.25 \mu \mathrm{M})$ promoted $30 \%$ more endothelial tube formation than control. Moreover, SFN affected intercellular communication between ECs and pericytes via inhibition of angiogenic factor such as vascular endothelial growth factor (VEGF) expression in pericytes. However, the expression of its receptor (VEGFR-2) was found significantly increased in ECs. These effects were associated with downregulation of prolyl hydroxylase domain-containing protein 1 and 2
\end{abstract}

Correspondence to: Dr Yongping Bao, Norwich Medical School, University of East Anglia, Norwich, Norfolk NR4 7UQ, UK

E-mail: y.bao@uea.ac.uk

Dr Ming Liu, The Fourth Affiliated Hospital, Harbin Medical University, Harbin, Heilongjiang 150001, P.R. China

E-mail:mliu35@aliyun.com

Abbreviations: DMSO, dimethyl sulfoxide; ECs, endothelial cells; EGM-2; endothelial growth medium-2; FBS, detal bovine serum; HIF-1 $\alpha$, hypoxia-inducible factor-1 $\alpha$; HUVECs, human umbilical vein endothelial cells; ITCs, isothiocyanates; MTT, 3-(4,5-dimethyl-2-thiazolyl)-2,5-diphenyl-2-H-tetrazolium bromide; Nfr2, NF-E2-related factor 2; PHD, prolyl hydroxylase; PVC, pericytes; ROS, reactive oxygen species; SFN, sulforaphane; TrxR1, thioredoxin reductase 1; VEGF, vascular endothelial growth factor; VEGFR, vascular endothelial growth factor receptor

Key words: sulforaphane, angiogenesis, VEGF, HUVEC, pericyte
(PHD1/2) and activation of hypoxia-inducible factor-1 (HIF) pathway by SFN. Furthermore, thioredoxin reductase-1 was also upregulated by SFN treatment, suggesting that antioxidant and redox regulation are involved in angiogenesis. Taken together, the results of the present study suggest that SFN differentially regulates endothelial cells and pericytes disrupting their interplay through the VEGF-VEGFR signalling pathway. Anti-angiogenesis property of SFN indicates that it has potential role as an anticancer agent.

\section{Introduction}

Angiogenesis, the growth of new capillary blood vessels, is a normal and vital process in growth, development and wound healing. However, it is also a fundamental step in the growth of tumours. Nutrients and oxygen, supplied by the blood vessels into the tumours, are essential for the growth and progression of malignant tumours beyond the size of $1-2 \mathrm{~mm}^{3}$ (1). Newly formed blood vessels can facilitate cells escaping through leakage from primary tumour sites to metastasize, the major cause of mortality for cancer patients. Anti-angiogenesis has been recognized as valuable therapy in treatment of various metastatic cancers since the theory was first proposed by Folkman $(2,3)$. Tumour angiogenesis is believed to be regulated by the interactions between pro-angiogenic and anti-angiogenic factors in the tumour microenvironment (4). Angiogenic response is a dynamic process requiring a series of fine-tuned angiogenic signalling and molecular events. Hypoxia is the common inducer of angiogenesis in the core of large tumours stimulating the release of pro-angiogenic factors to promote endothelial cell proliferation, migration, differentiation and self-assembly into vascular-like structures. Subsequently, perivascular cells are recruited to form mature and stable vessels (5).

The interaction between endothelial cells (ECs) and pericytes (PVCs) has gained increasing attention as a central process in the regulation of blood microvascular structures as well as in their stabilization and maturation. Aberrant interplays between the two cell types have been observed in a multitude of human pathological conditions, including cancer angiogenesis (6). Targeting one cell type, either ECs or PVCs may produce limited effects. The most effective therapies will probably involve targeting multiple mediators, 
and will require improving the efficiency of drug delivery to the tumour microenvironment $(7,8)$. Therefore, improving the therapeutic response will require consideration of various signalling pathways and cell types involved in the vascular component of cancer.

Hypoxia-inducible factor-1 (HIF-1 $\alpha$ ) dependent hypoxiainduced response is tightly controlled by HIF-prolyl hydroxylase domain (PHD) which targets HIF-1 $\alpha$ for degradation. Oxygen-dependent PHDs negatively regulate HIFs and, crucially, confer its oxygen sensitivity. In the presence of oxygen, PHD2 hydroxylates HIF-1 $\alpha$ on two specific proline residues, which results in its destruction. In hypoxia, PHD2 is missing its co-substrate (oxygen), rendering it inactive. HIF-1 $\alpha$ then becomes stabilized, and results in the upregulation of angiogenic factors such as vascular endothelial growth factor (VEGF), fibroblast growth factor (FGF)-2 and angiopoietin-2 thereby promoting neovascularization. Hypoxia also inactivates PHDs, causing accumulation of HIF-1 $\alpha$ which in turn further transactivates PHDs. This feedback loop ensures the homeostasis of HIF-1 $\alpha$ activity caused by hypoxia $(9,10)$.

After VEGF is released from tumour cells, it binds to two cognate VEGF receptors, VEGF receptor 1 (VEGFR1) and VEGF receptor 2 (VEGFR2/KDR/flk-1), which are expressed on local vascular ECs (11). Signalling through VEGFR1/2 drives the process of angiogenesis, which involves dissolution of the vascular basement membrane, endothelial cell proliferation and formation of new blood vessels (12). The binding to VEGF receptor is a crucial step in initiation of EC proliferation, migration and differentiation during angiogenesis $(13,14)$. The VEGF signalling system has been suggested as a highly 'druggable' target and potent inhibitors of the VEGF signalling pathway have been used clinically including bevacizumab, sunitinib and sorafeib (15-17). To date, targeting the HIF/VEGF-VEGFR axis has been a promising strategy for cancer therapy (18). Anti-VEGF-VEGFR therapies may also have immunological effects (19). Since HIF signalling contributes to the acquisition of resistance against anti-VEGF therapy, the combined blockade of VEGF and HIF-1 $\alpha$ is being explored as a cancer treatment strategy (5). Despite the indisputable success of anti-angiogenic drugs in the clinical treatment for some advanced solid cancers, there are difficulties with regard to the control of the activities of these drugs and of the identification of patients who are sensitive to them (20).

Epidemiological studies have demonstrated that cruciferous vegetables can reduce the risk of various types of cancers in humans $(21,22)$. Sulforaphane (SFN) is one of the most extensively studied isothiocyanates (ITCs) from broccoli and cauliflower. SFN has been found to suppress tumour cell growth through multiple molecular mechanisms including induction of cell cycle arrest and apoptosis in many types of tumour cells (23-26). SFN has been shown to inhibit ECs proliferation via apoptosis and autophagy (27-29) and suppress VEGF and MMP-2 expression $(30,31)$, the latter being associated with the inhibition of FOXO1/AKT pathways (32). Moreover, SFN is a known inducer of both thioredoxin reductase (TrxR1) and thioredoxin $(26,33)$, which are involved in inflammation, apoptosis, angiogenesis, embryogenesis and cardiovascular disease involved in angiogenesis (34). The molecular mechanisms of SFN suppression of angiogenesis, in particular the effects on signalling pathways between ECs and pericytes in response to SFN treatment, are not fully understood. In the present study a coculture of primary human umbilical vein endothelial cells (HUVECs) and pericytes in a 3D collagen gel model were used to dissect the mechanism by which SFN interacts with crosstalk between these two key cell types in angiogenesis. Understanding the interactions between HUVECs and pericytes under SFN treatment may contribute to the development of novel agents in anti-angiogenetic therapy.

\section{Materials and methods}

Reagents. SFN (4-methylsulfinylbutyl isothiocyanate) was purchased from Toronto Research Chemicals, Inc. (North York, ON, Canada). High concentration rat tail type-I collagen solution and purified mouse anti-human CD31/PECAM (555444) antibody were both purchased from BD Biosciences (Oxford, UK). Polyclonal donkey anti-mouse $\mathrm{Cy} 3$ was purchased from Abcam (Cambridge, UK). Growth factors PDGF-BB and bFGF were obtained from Gibco/Life Technologies (Paisley, UK). The primary antibodies against HIF-1 $\alpha$ (ab2185), VEGF (sc7269), Flk1 (sc6251), TrxR1 (sc20147 were purchased from Santa Cruz Biotechnology (Heidelberg, Germany). The primary antibodies against PHD1 (ab80361) and PHD2 (ab83560) were purchased from Abcam. Secondary antibodies were from Santa Cruz Biotechnology. siRNA for TrxR1 and AllStars (AS) negative control were all purchased from Qiagen (West Sussex, UK). Electrophoresis and western blotting supplies were obtained from Bio-Rad Laboratories (Hemel Hempstead, UK) and the chemiluminescence kit was from GE Healthcare (Little Chalfont, UK).

Cell culture. HUVECs were obtained from TCS Cellworks and used between passages 2 and 8 for all experiments. The cells were grown in plastic flasks pre-treated with $10 \mu \mathrm{g} / \mathrm{ml}$ type-I collagen (BD Biosciences) in phosphate-buffered saline (PBS) for $30 \mathrm{~min}$ in $37^{\circ} \mathrm{C}$ incubator. Endothelial growth medium-EGM2 (C22011; PromoCell, Birmingham, UK) with supplements was used as culture medium for HUVECs according to the manufacturer's protocols. Murine perivascular cells (PVC) were isolated as previously described and used between passages 32 and 38 (35). Pericytes were routinely incubated in Dulbecco's modified Eagle's medium (DMEM) containing $10 \%$ fetal bovine serum (FBS). All cells were incubated at $37^{\circ} \mathrm{C}$ in $95 \%$ humidified air containing $5 \% \mathrm{CO}_{2}$.

Cell viability assay. The MTT assay was used to examine the toxicity of SFN in HUVECs and pericytes. Cells were seeded in 96-well plates and cultured in an incubator at $37^{\circ} \mathrm{C}$ to $\sim 70-80 \%$ confluence. Cultured cells were treated with concentrations $(1.25-160 \mu \mathrm{M})$ of SFN or DMSO $(0.1 \%$ as control) for $24 \mathrm{~h}$ with four replicate wells per treatment. After all treatments, the medium was removed and fresh medium $(100 \mu \mathrm{l})$ was added together with $10 \mu \mathrm{l}$ MTT solution $(5 \mathrm{mg} / \mathrm{ml})$, then incubated at $37^{\circ} \mathrm{C}$ for $1 \mathrm{~h}$ to allow the MTT to be metabolized. The formazan produced was re-suspended in $100 \mu \mathrm{l}$ of dimethyl sulfoxide (DMSO)/well. The final absorbance in the wells was quantified using a microplate reader (BMG Labtech Ltd., Aylesbury, UK) at a test wavelength of $570 \mathrm{~nm}$ and a reference wavelength of $670 \mathrm{~nm}$. Viability of treated cells was expressed 
as a percentage of control as follows: (A570 nm-A670 nm) sample/(A570 nm-A670 nm) control x 100. The $\mathrm{IC}_{50}$ was determined using CalcuSyn software version 2.0 (Biosoft, Cambridge, UK).

$3 D$ co-culture in collagen gel. Capillary-like tube formation in $3 \mathrm{D}$ collagen matrices of co-culture with HUVEC and pericytes was used to test the angiogenic effects of SFN. Collagen type I gels $(2 \mathrm{mg} / \mathrm{ml})$ were prepared in $1 \mathrm{X}$ DMEM medium from concentrated rat tail type I collagen solution $(>8 \mathrm{mg} / \mathrm{ml}$ in $0.02 \mathrm{M}$ acetic acid; BD Biosciences) at $4^{\circ} \mathrm{C}$, supplemented with final concentrations of $2 \% \mathrm{FBS}, 22.5 \mathrm{mM} \mathrm{NaHCO}, 1 \mathrm{mM}$ sodium pyruvate and neutralized with $0.1 \mathrm{~N} \mathrm{NaOH}$ according to the supplier's instructions. Cells were trypsinised, washed with PBS, counted and desired cell numbers were collected by centrifugation. Cells were suspended in the collagen I gel solution at $4^{\circ} \mathrm{C}$ and $400 \mu \mathrm{l}$ suspension added per well into 24-well plates. After an initial incubation at $37^{\circ} \mathrm{C}$ for $20 \mathrm{~min}, 400 \mu \mathrm{l}$ EGM2 culture medium containing $\mathrm{SFN}(0.6-20 \mu \mathrm{M})$ or $0.1 \%$ DMSO (control) was added to solidified collagen I gels with supplements to achieve final concentrations of $10 \mathrm{ng} / \mathrm{ml}$ for VEGF and PDGF, respectively, and $250 \mu \mathrm{g} / \mathrm{ml}$ ascorbic acid phosphate. Typical experiments contained $2.5 \times 10^{5}$ HUVEC and/or $0.5 \times 10^{5} \mathrm{PVC} /$ well, unless otherwise stated. Medium was changed every $24 \mathrm{~h}$ and cultures were maintained for up to 5 days.

Immunostaining of HUVEC-pericyte coculture model. Immunohistochemical analyses of cell cultures were performed as described by Brachvogel et al (36) and Zhou et al (37). Whole mount immunohistochemistry of 3D collagen cultures was performed as described by Bader et al (38). Briefly, gels were washed in PBS, fixed with $80 \%$ methanol/20\% DMSO for $30 \mathrm{~min}$ at $20^{\circ} \mathrm{C}$ (or $16 \mathrm{~h}$ at $4^{\circ} \mathrm{C}$ ), then rehydrated in $50 \%$ methanol/PBS, 20\% methanol/PBS and PBS-T (PBS, $0.1 \%$ Tween-20) for $1 \mathrm{~h}$ each and then incubated with blocking buffer (10\% FBS, 5\% BSA in PBS) for 2-4 h at room temperature or $16 \mathrm{~h}$ at $4^{\circ} \mathrm{C}$. Gels were incubated with primary antibodies in blocking buffer for $16 \mathrm{~h}$ at $4^{\circ} \mathrm{C}$ and then washed 7 times for $1 \mathrm{~h}$ each in TBS-T (TBS, 01\% Tween-20) followed by incubation with fluorescently labelled secondary antibodies in blocking buffer for 2-16 $\mathrm{h}$ and then washed again as described above. After nuclear staining, samples were mounted in Gelvatol and examined by fluorescence microscopy (SteREO LumarV12 and Axioplan2; Carl Zeiss, Oberkochen, Germany). Pictures of fluorescent signals were captured by a black-white camera and colour-coded by AxioVision software (version 4.5).

Western blot analysis of protein expression. HUVECs and PVC cells were treated with SFN (1-20 $\mu \mathrm{M})$ or DMSO $(0.1 \%$ as control) at $70-80 \%$ confluence. Total protein was extracted by washing cells twice with ice-cold PBS and harvested by scraping in $20 \mathrm{mM}$ Tris- $\mathrm{HCl}$ (pH 8.0), $150 \mathrm{mM} \mathrm{NaCl}, 2 \mathrm{mM}$ EDTA, $10 \%$ glycerol, 1\% Nonidet P-40 (NP-40) containing mini-complete proteinase inhibitor. The cell suspension/lysate was placed in an ice bath for $20 \mathrm{~min}$ and then centrifuged at $12,000 \mathrm{x} \mathrm{g}$ for $15 \mathrm{~min}$ at $4^{\circ} \mathrm{C}$. Protein concentrations were determined using the Brilliant Blue $\mathrm{G}$ dye-binding assay of Bradford using BSA as a standard. Equivalent aliquots of protein were mixed with 4 X SDS-PAGE sample buffer and DTT reducing agent (to $50 \mathrm{nmol} / \mathrm{l}$ ) and were heated to $95^{\circ} \mathrm{C}$ for $5 \mathrm{~min}$. Equal amounts of samples were loaded onto SDS-PAGE gel and subsequently transferred to PVDF (polyvinylidene difluoride) membranes (Bio-Rad Laboratories). The membrane was washed three times for 45 min with PBST and then incubated with the secondary antibody diluted with $5 \%$ milk in PBST for $1 \mathrm{~h}$. After further washing the membrane three times for 45 min with PBST, antibody binding was determined by a chemiluminescence detection kit and densitometry was measured by Fluor ChemImager (Alpha Innotech, San Leandro, CA, USA).

Statistical analysis. All experiments were independently repeated at least three times. Data are means \pm SD. Student's t-test was applied for differences between groups using SPSS software. Significant differences among groups were calculated and $\mathrm{P}<0.05$ was viewed as statistically significant.

\section{Results}

Effect of SFN on cell proliferation and viability in HUVECs and $P V C$. As a viable and adequate population of HUVECs and PVC is essential for angiogenesis, the effect of SFN on cell proliferation and viability of both cell types were measured by treating the cells with SFN over a range of concentrations (0.625-160 $\mu \mathrm{M})$ for 24 and $48 \mathrm{~h}$ followed by an MTT assay. At low doses, from 0.625 to $5 \mu \mathrm{M}$, SFN has no toxic effect on cell viability. SFN at $2.5 \mu \mathrm{M}(24 \mathrm{~h})$ promoted cell proliferation to 116 and $136 \%$ in HUVECs and PVC, respectively (Fig. 1). However, a dose-dependent effect on cell viability was observed following treatments with SFN between 20 and $160 \mu \mathrm{M}$, i.e. cell viability decreased to $83.8 \%$ and $<10 \%$ respectively, $\mathrm{IC}_{50}, 46.7 \mu \mathrm{M}$. In parallel, the influence of SFN on PVC was also determined, and a similar dose-dependent effect on cell viability was observed. In both cell types, there was no significant difference in cell viability after exposure to $10 \mu \mathrm{M}$ SFN at 24 and $48 \mathrm{~h}$ although the PVCs are slightly more sensitive to SFN with $\mathrm{IC}_{50}, 32.4 \mu \mathrm{M}$. Based on these results, $10 \mu \mathrm{M}$ SFN was chosen as an optimum dosage for the tube formation experiments and 1-20 $\mu \mathrm{M}$ were used for mechanistic studies.

SFN suppresses capillary formation in $3 D$ collagen model of HUVECs and PVC co-culture. The tube formation assay in $3 \mathrm{D}$ collagen gel is a well-established procedure for the evaluation of angiogenic capacities. To detect the angiogenic effect of SFN, a co-culture model consisting of HUVECs and pericytes was used to mimic more realistically the in vivo angiogenic process. Angiogenic growth factors were present in the collagen matrix in order to more closely represent a tumour microenvironment to promote capillary-like tube formation through ECs alignment with supporting pericytes. In the vehicle control (0.1\% DMSO), HUVECs and pericytes formed robust capillary structures. The addition of SFN to the growth medium of the co-culture collagen gel, led to a concentrationdependent disruption of the tube structure. The formation of tube structures were only partially inhibited at moderate SFN concentrations (2.5-10 $\mu \mathrm{M})$ whilst higher dosages $(20 \mu \mathrm{M})$ completely inhibited the formation of tube structures (Fig. 2A). Notably, SFN at low concentrations from 0.625 to $1.25 \mu \mathrm{M}$ promoted the formation of tubes by $115-120 \%$ of the 

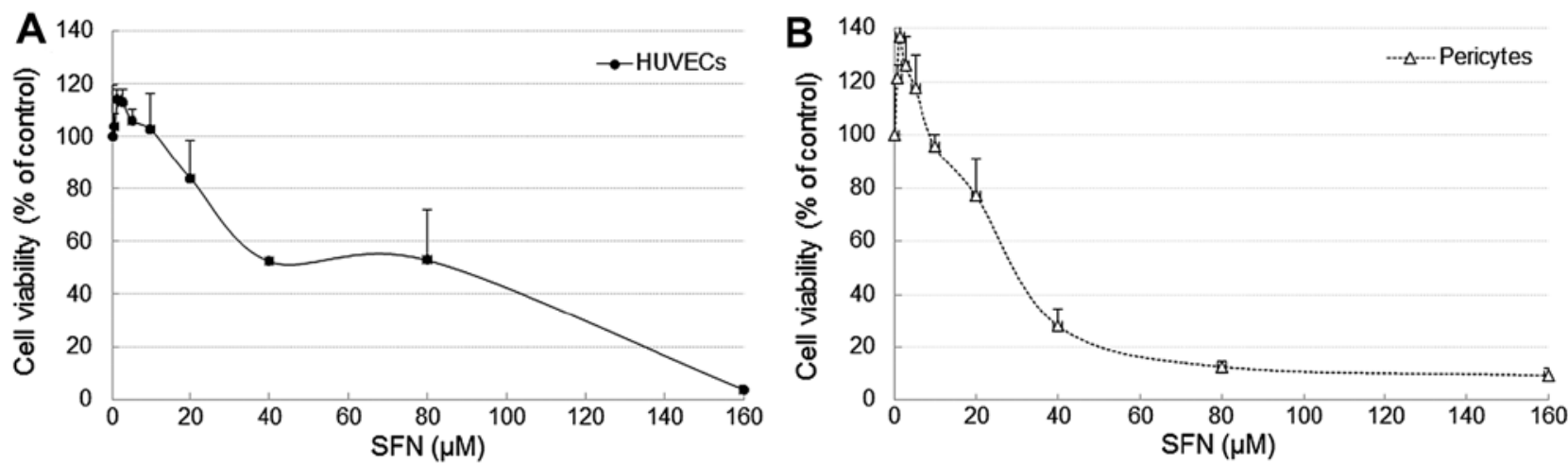

Figure 1. Effect of SFN on cell viability in HUVECs and pericytes. Dose-dependent effect of SFN on cell viability in (A) HUVECs and (B) pericytes. Exponentially growing cells were treated with SFN $(0-160 \mu \mathrm{M})$ for 24 and $48 \mathrm{~h}$. Cell viability was measured by MTT assay. Each concentration was tested in quadruplicate and the experiment was repeated twice. Results were present as $\%$ of control. ${ }^{*} \mathrm{P}<0.05$ compared with control.

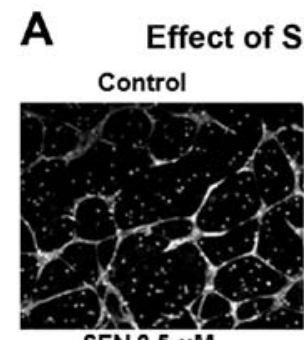

SFN $2.5 \mu \mathrm{M}$

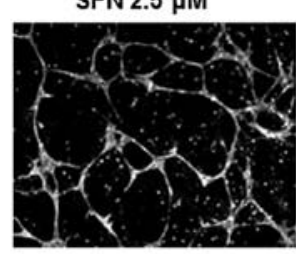

B

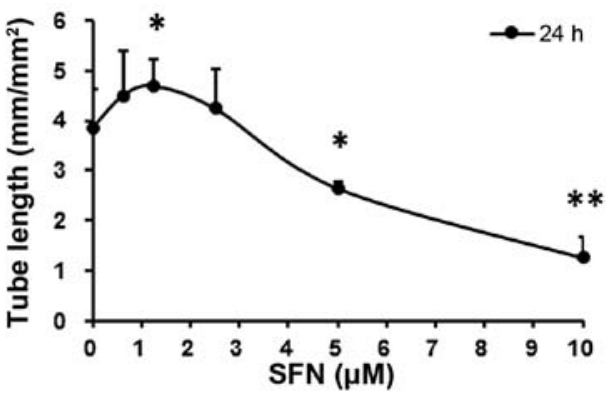

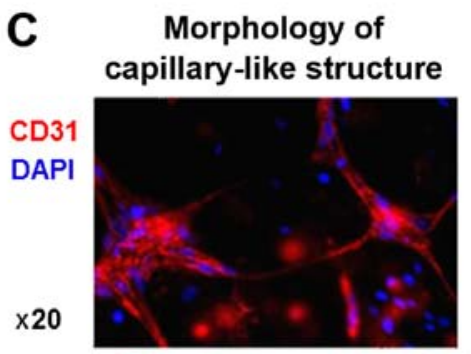

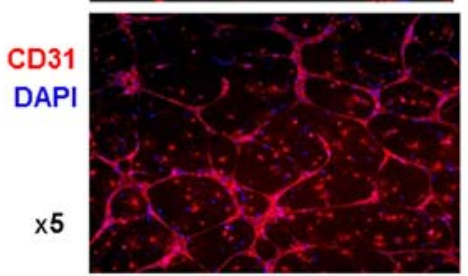

Figure 2. Effect of SFN on capillary formation in 3D culture of HUVECs and pericytes. (A) Representative images show dose-dependent effect of SFN for $24 \mathrm{~h}$ in the 3D tube model of co-culture HUVECs with pericytes (magnification, $\mathrm{x} 5$ ). Images were taken by optical micrographs after $24 \mathrm{~h}$. (B) Line chart represents cumulative tube length of 3D co-culture model exposed to SFN (0-20 $\mu \mathrm{M})$. (C) Morphology of capillary-like structures in untreated control. Data are representative of three independent experiments. ${ }^{*} \mathrm{P}<0.05 ;{ }^{* *} \mathrm{P}<0.01$.

control, i.e. total tube length was $3.86 \mathrm{~mm} / \mathrm{mm}^{2}$ in control and $4.69 \mathrm{~mm} / \mathrm{mm}^{2}$ in SFN $(1.25 \mu \mathrm{M})$ treated cells (Fig. 2B). Immunostaining of control cells with anti-CD31 and DAPI showed capillary-like morphology in the untreated HUVECs and PVCs (Fig. 2C).

Effect of SFN on VEGF and VEGFR2 expression. To evaluate whether SFN inhibits VEGF expression, PVC were cultured in EGM2 medium for $24 \mathrm{~h}$ followed by a dose-dependent (1.25-20 $\mu \mathrm{M})$, or a time course $(0-24 \mathrm{~h})$ of treatment with SFN $(10 \mu \mathrm{M})$. Western blot analysis for VEGF protein expression demonstrated that SFN inhibits VEGF in PVC in a dose- and time-dependent manner (Fig. 3A and B). SFN inhibited VEGF expression to 60 and $30 \%$ of the control after the treatments with 5 and $20 \mu \mathrm{M} \mathrm{SFN} \mathrm{(24} \mathrm{h),} \mathrm{respec-}$ tively. An inhibitory effect of $10 \mu \mathrm{M}$ SFN was also observed after $3 \mathrm{~h}$ ( $70 \%$ of control), $12 \mathrm{~h}$ (48\% of control) and $24 \mathrm{~h}$ (36\% of control) treatment (Fig. 2B). However, VEGF was not at detectable level in similarly treated HUVECs (data not shown). To further investigate VEGF and its receptor signalling pathway, the effect of SFN on VEGFR2 protein expression was determined. Not surprisingly, PVCs do not 


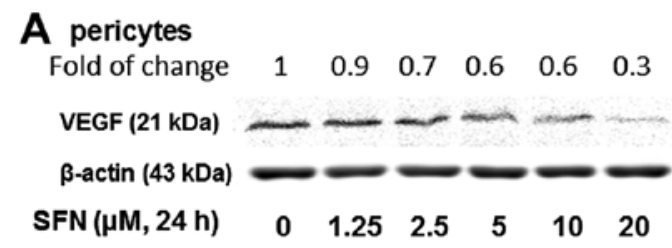

C HUVECS

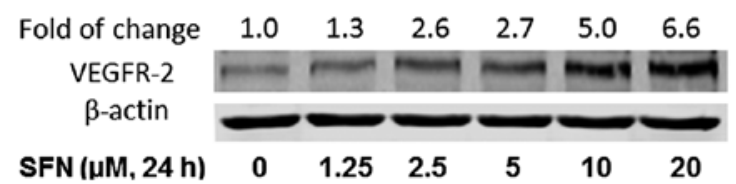

B pericytes

$\begin{array}{llllllll}\text { Fold of change } & 1.0 & 1.0 & 0.7 & 1.0 & 0.48 & 1.0 & 0.36\end{array}$

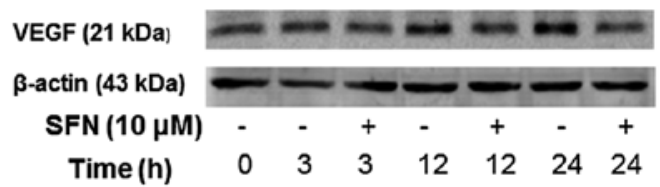

D HUVECs

$\begin{array}{lllllll}\text { Fold of change } & 1.0 & 1.7 & 2.8 & 2.6 & 5.7 & 5.0\end{array}$

VEGFR-2 =

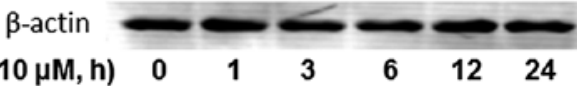

Figure 3. Effect of SFN on VEGF and VEGFR2 expression in HUVECs and pericytes. (A) Pericyes were treated with SFN (1.25-20 $\mu \mathrm{M})$ for $24 \mathrm{~h}$; Control was DMSO at $0.1 \%$. (B) Cells were treated with SFN $10 \mu \mathrm{M}$ for 1,3,6, 12 and $24 \mathrm{~h}$. Time 0 was control (DMSO 0.1\%). All pericytes were cultured in DMEM medium then replaced by EGM2 medium $24 \mathrm{~h}$ before SFN treatments. (C) HUVECs were treated with SFN (1.25-20 $\mu \mathrm{M})$ for $24 \mathrm{~h}$; SFN 0 was control (DMSO $0.1 \%$ ). (D) HUVECs were treated with SFN $10 \mu \mathrm{M}$ for 1,3, 6, 12 and $24 \mathrm{~h}$. Equal amounts of cellular protein (80 $\mu \mathrm{g})$ were loaded, and resolved by SDS/10\% PAGE and western blot analysis. Data are representative of three independent experiments.

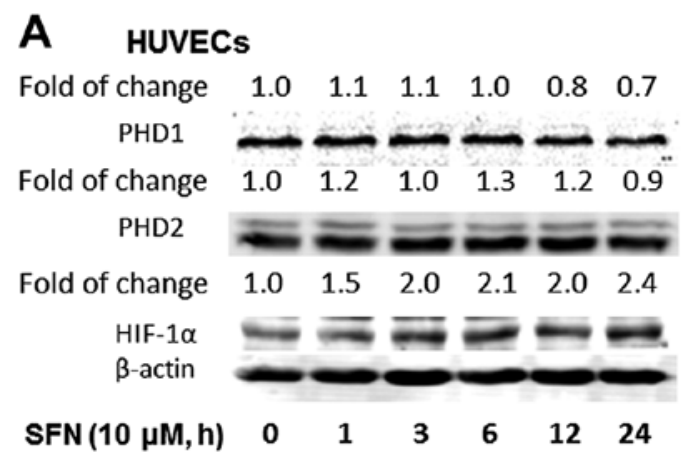

\section{B}

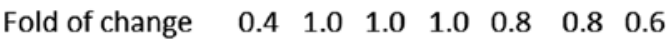

PHD1

Fold of change $\quad \begin{array}{llllllll}1.2 & 1.0 & 1.1 & 0.9 & 0.8 & 1.0 & 0.8\end{array}$ PHD2

$\begin{array}{lllllllll}\text { Fold of change } \quad 0.3 & 1 & 1.2 & 1.1 & 1.3 & 4.2 & 2.7\end{array}$

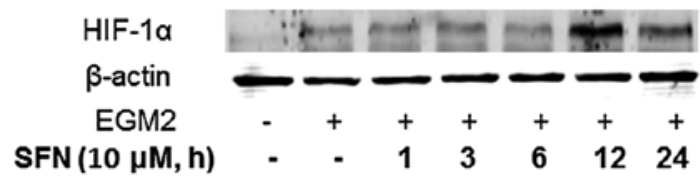

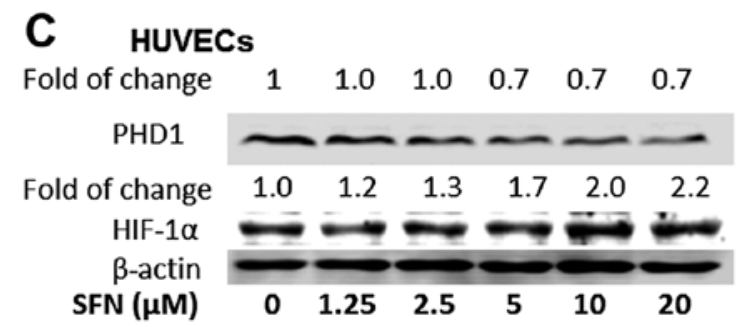

Figure 4. Effect of SFN on HIF-1 $\alpha$, PHD1 and PHD2 expression in HUVECs and pericytes. (A) HUVECs were treated with SFN (10 $\mu$ M) and whole protein was isolated at 1, 3, 6, 12 and $24 \mathrm{~h}$. Time 0 cells was treated with DMSO (0.1\%) as control. (B) HIF-1 $\alpha$, PHD1 and PHD2 were detected in pericytes after exposure to SFN (10 $\mu \mathrm{M}$ for 1 to $24 \mathrm{~h}$ ) using western blot analysis. Cells grown to $\sim 50-60 \%$ confluence in DMEM medium, then replaced by EGM2 medium and incubated for further $24 \mathrm{~h}$ before SFN treatment. In the DMEM only group, cells were cultured and treated with SFN (10 $\mu$ M). (C) HUVECs were treated with SFN (1.25-20 $\mu \mathrm{M})$ for $24 \mathrm{~h}$. Data are representative of three independent experiments.

express detectable levels of VEGFR2 (data not shown), whilst HUVECs showed a significant upregulation of VEGF-R2 level after SFN treatment (Fig. 3C and D).

Differential regulation of HIF signalling pathway after SFN exposure. HIF pathway is an important signaling pathway for HIF secretion especially in tumour micro-environments. In the present study, HIF-1 $\alpha$, PHD1 and PHD2 protein expression in both HUVECs and PVC were quantified by western blot assay. Both cell types were treated with $10 \mu \mathrm{M}$ SFN for different time periods (1, 3, 6, 12 and $24 \mathrm{~h})$ and HIF-1 $\alpha$ and the relative expressions in both types of cells were measured. SFN increased HIF-1 $\alpha$ expression in both cell types, i.e. 2.0to 2.4-fold in HUVECs and 4.2-2.7-fold in PVC at 12 and $24 \mathrm{~h}$, respectively (Fig. 4A and B). As expected, the effect of SFN on the expression of PHD1 was suppressed by SFN, $30 \%$ in HUVECs and $40 \%$ in pericytes at $24 \mathrm{~h}$ of treatment. Moreover, increasing SFN concentration in HUVECs from 1.25 to $20 \mu \mathrm{M}$ for $24 \mathrm{~h}$, had no significant effect on PHD1 protein expression, but again increased HIF-1 $\alpha$ expression (Fig. 4C). Activation of HIF-1 $\alpha$ may associate with the low-dose promotion effect of SFN on cell growth. 


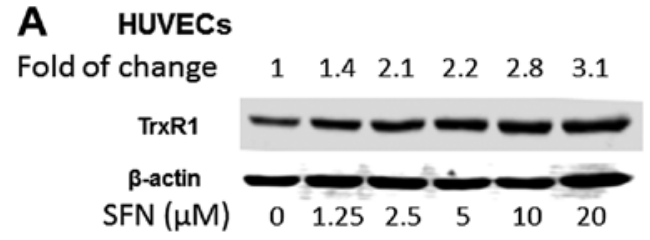

B HUVECS

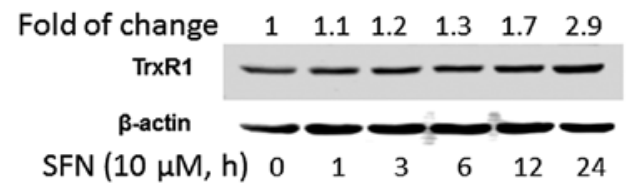

C pericytes
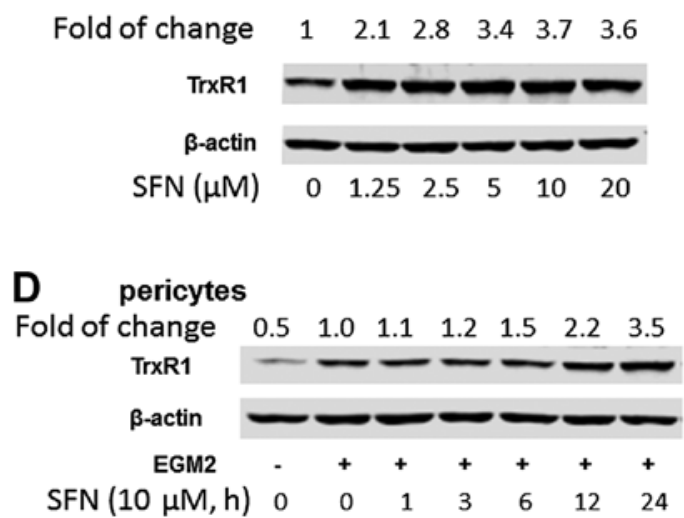

Figure 5. Effect of SFN on TrxR1 protein expression in HUVECs and pericytes. (A) HUVECs were treated with SFN (1.25-20 $\mu \mathrm{M}$ ) for 24 h. (B) HUVECs were treated with SFN $10 \mu \mathrm{M}$ for different times (1, 3, 6, 12 and $24 \mathrm{~h}$ ). (C) Pericytes were treated with SFN (1.25-20 $\mu \mathrm{M})$ for $24 \mathrm{~h}$. (D) Pericytes were treated with SFN $(10 \mu \mathrm{M})$ for 1, 3, 6, 12 and $24 \mathrm{~h}$. All pericytes were cultured in DMEM medium (50-60\%) until being replaced by EGM2 medium and incubated for $24 \mathrm{~h}$ before SFN treatment for another $24 \mathrm{~h}$.

Effect of SFN on TrxR1 expression. Inhibition of thioredoxin reductase ( $\operatorname{Trx} \mathrm{R} 1$ ) has been shown to regulate angiogenesis by increasing endothelial cell-derived VEGF (39). SFN increased TrxR1 expression in both HUVECs and PVC dose- and time-dependently, i.e. SFN at $10 \mu \mathrm{M}$ induced TrxR1 2.8- and 3.7-fold in HUVECs (Fig. 5A and B) and PVC (Fig. 5C and D), respectively. TrxR1 plays an important role in SFN inhibition of angiogenesis. Knockdown of TrxR-1 abolished the downregulation of PHD1 by SFN treatment $(10 \mu \mathrm{M}, 24 \mathrm{~h})$, suggesting a deficiency of TrxR-1 may cause the accumulation of PHD1. However, knockdown of TrxR1 only attenuated $\sim 20 \%$ of the SFN-inhibited tube formation (data not shown) suggesting that the inhibition of tube formation by SFN is only partly TrxR1-dependent.

\section{Discussion}

In the present study, we demonstrated that SFN exhibited differential effect on the regulation of angiogenesis in ECs and pericytes which may interrupt the crosstalk mechanism between them leading to reduced angiogenic capacity. Conventional planar cultures fail to recreate the in vivo physiology of the microvasculature with respect to $3 \mathrm{D}$ geometry (lumens and axial branching points) and interactions of endothelium with perivascular cells, extracellular tissue and blood flow $(40,41)$. There is strong evidence that the $3 \mathrm{D}$ in vitro model consisting of multiple stromal cells is not only cheaper but also provides quicker results than animal models. Additionally, 3D models are more analogous to pathological progression of angiogenesis than $2 \mathrm{D}$ cell culture models. Herein, we set up a 3D collagen model of HUVECs and pericytes in co-culture with growth factors to closely mimic the angiogenesis process in vivo microenvironment, and to allow the detection of the effects of dietary bioactives such as SFN, and the delineation of the molecular mechanisms of SFN in the interactions between HUVEC and PVCs.

SFN affected the network structure of neovascularization, causing disruption at concentrations $>5 \mu \mathrm{M}$ dose- and timedependently. A marked increase in microvessel formation at lower doses between 0.625-1.25 $\mu \mathrm{M}$ was also observed. This bell-shaped effect (hormesis) is common in anticancer agents $(15,42)$ which suggests the importance of maintaining the SFN at high concentrations $(>5 \mu \mathrm{M})$ for cancer chemoprevention or treatment. These tube formation results were consistent with the cell viability data that showed that SFN inhibited the growth of ECs at concentrations of 5-20 $\mu \mathrm{M}$ while at low concentrations of $0.625-2.5 \mu \mathrm{M}$, SFN promoted cell growth. Our findings suggest that the multi-targeted effect of SFN in EC-pericyte coculture model and on proliferation of ECs, demonstrates that its mechanism of action is complex. The biphasic effects of SFN on angiogenesis indicate that lower concentrations may provide benefit in conditions where the formation of an inadequate number of new blood vessels prevent an adequate blood supply, such as many cardiovascular diseases. In contrast, high concentrations of SFN (in the present study, 5-20 $\mu \mathrm{M}$ ) are needed for the anti-angiogenic effects.

At the level of protein expression, SFN treatment was found to inhibit VEGF secretion from pericytes but upregulate VEGF receptor-2 expression in ECs. VEGF, one of the major angiogenesis factors, is induced in growing tumours and stimulates EC proliferation and migration primarily through the VEGFR2 (Flk1/KDR) pathway (43). HIF-1 is overexpressed in many human cancers and it regulates the expression of VEGF. Yao et al (23) demonstrated the inhibitory effect of SFN on HIF-1 $\alpha$ and VEGF expression in human SCCs and prostate cancer cells via multiple pathways. Bertl et al (31), reached a similar conclusion in their study. The HIF pathway is also responsible for acquisition of resistance against anti-VEGF therapy. Our results contradict some other findings that SFN was found to have unique character by activating HIF-1 $\alpha$ pathway in both HUVECs and PVC but supressing VEGF expression in PVC. The exact mechanism is not clear but early research has revealed other transcription factors are also involved in VEGF expression, such as Sp1/ Sp3, AP2, Egr-1 and STAT-2 (44). For example, SFN was found to be able to inhibit STAT and SP1 pathways $(45,46)$. Our finding may suggest that SFN has a potential role in attenuating anticancer resistance. 
TrxR1, an Nrf2-driven selenoprotein, was upregulated by SFN and may increase the anti-oxidant and redox regulation capability. The increase in TrxR1 expression following SFN treatment $(10 \mu \mathrm{M})$ was found time- and dose-dependently (Fig. 4).

TrxR1 is involved in cell proliferation, redox regulation of gene expression and signal transduction, protection against oxidative stress, anti-apoptotic functions and regulation of the redox state of the extracellular environment (47). Upregulation of TrxR1 plays a role in protection against free-radical mediated cell death (48). In this study, knockdown of TrxR1 attenuated $20 \%$ SFN inhibition of tube formation, and co-treatment of HUVECs/PVC with SFN and N-acetylcysteine (NAC) at $2 \mathrm{mM}$ abolished the promoting effect of low dose SFN on tube formation (data not shown). This indicates the involvement of reactive oxygen species (ROS) $(49,50)$. However, excessive ROS production may play a role in microvascular instability (51).

It is well accepted that angiogenesis is a critical, ratelimiting step in the development of cancers and its inhibition suppresses tumour growth, progression and metastases. Antiangiogenic therapy using dietary compounds represents a new cost-effective approach to the early intervention and prevention of cancer (52). There are many natural and synthetic antioxidants such as curcumin, tea polyphenols and vitamins $\mathrm{E}$ and $\mathrm{C}$ that possess anti-angiogenic activities (53) and there is significant potential in the further investigation of their interactions in modulation of angiogenesis. Dietary isothiocynates such as SFN, derived from glucoraphanin from cruciferous vegetables, have attracted much attention for their potential to prevent various types of cancers. SFN may protect endothelium from oxidative stress by inducing TrxR1 expression and activity and also by suppressing the activation of MAPKs $(38,54)$. When 5-20 $\mu \mathrm{M} \mathrm{SFN}$ was used, the expression of TrxR1 was increased and this is associated with resistance to inflammation (55). The downregulation of angiogenic signalling pathways by SFN could offer a new therapeutic strategy in suppressing malignant tumour progression, especially if multiple molecules were targeted and suppressed in cells responsive to SFN potentiated modulation of the angiogenic process. The results from the present study strongly indicate a potential role of SFN at higher doses in anti-angiogenesis cancer therapy. The action of SFN in targeting HIF, PHD and VEGF in the interplay between ECs and pericytes may shed insights into new treatment strategies. Therefore, the therapeutic potential of SFN as a potential alternative anti-VEGF agent in chemoprevention is worthy of further exploration in animal models and small scale human trials.

\section{Acknowledgements}

The authors are grateful to Mr. Jim Bacon for careful reading of the manuscript. The present study was supported, in part, by an award from the Cancer Prevention Research Trust, UK and an award from the National Natural Science Foundation of China (NSFC no. 81372612).

\section{References}

1. Folkman J: Role of angiogenesis in tumor growth and metastasis. Semin Oncol 29 (Suppl 16): 15-18, 2002.
2. Sharma RA, Harris AL, Dalgleish AG, Steward WP and O'Byrne KJ: Angiogenesis as a biomarker and target in cancer chemoprevention. Lancet Oncol 2: 726-732, 2001.

3. Folkman J: Tumor angiogenesis: Therapeutic implications. N Engl J Med 285: 1182-1186, 1971.

4. Hanahan D and Folkman J: Patterns and emerging mechanisms of the angiogenic switch during tumorigenesis. Cell 86: 353-364, 1996.

5. Carmeliet $P$ and Jain RK: Molecular mechanisms and clinical applications of angiogenesis. Nature 473: 298-307, 2011.

6. Armulik A, Abramsson A and Betsholtz C: Endothelial/pericyte interactions. Circ Res 97: 512-523, 2005.

7. Bergers G, Song S, Meyer-Morse N, Bergsland E and Hanahan D: Benefits of targeting both pericytes and endothelial cells in the tumor vasculature with kinase inhibitors. J Clin Invest 111: 1287-1295, 2003.

8. Weis SM and Cheresh DA: Tumor angiogenesis: Molecular pathways and therapeutic targets. Nat Med 17: 1359-1370, 2011.

9. Metzen E, Stiehl DP, Doege K, Marxsen JH, Hellwig-Bürgel T and Jelkmann W: Regulation of the prolyl hydroxylase domain protein 2 (phd2/egln-1) gene: Identification of a functional hypoxia-responsive element. Biochem J 387: 711-717, 2005.

10. Berra E, Richard DE, Gothié E and Pouysségur J: HIF-1-dependent transcriptional activity is required for oxygen-mediated HIF-lalpha degradation. FEBS Lett 491: 85-90, 2001.

11. Olsson AK, Dimberg A, Kreuger J and Claesson-Welsh L: VEGF receptor signalling - in control of vascular function. Nat Rev Mol Cell Biol 7: 359-371, 2006.

12. Carmeliet P: Mechanisms of angiogenesis and arteriogenesis. Nat Med 6: 389-395, 2000.

13. Xie K, Wei D, Shi Q and Huang S: Constitutive and inducible expression and regulation of vascular endothelial growth factor. Cytokine Growth Factor Rev 15: 297-324, 2004.

14. Tang N, Wang L, Esko J, Giordano FJ, Huang Y, Gerber HP, Ferrara $\mathrm{N}$ and Johnson RS: Loss of HIF-1alpha in endothelial cells disrupts a hypoxia-driven VEGF autocrine loop necessary for tumorigenesis. Cancer Cell 6: 485-495, 2004.

15. Reynolds AR: Potential relevance of bell-shaped and u-shaped dose-responses for the therapeutic targeting of angiogenesis in cancer. Dose Response 8: 253-284, 2010.

16. Ferrara $\mathrm{N}$ and Kerbel RS: Angiogenesis as a therapeutic target. Nature 438: 967-974, 2005.

17. Ellis LM and Hicklin DJ: VEGF-targeted therapy: Mechanisms of anti-tumour activity. Nat Rev Cancer 8: 579-591, 2008.

18. Rapisarda A and Melillo G: Role of the VEGF/VEGFR axis in cancer biology and therapy. Adv Cancer Res 114: 237-267, 2012.

19. Terme M, Pernot S, Marcheteau E, Sandoval F, Benhamouda N, Colussi O, Dubreuil O, Carpentier AF, Tartour E and Taieb J: VEGFA-VEGFR pathway blockade inhibits tumor-induced regulatory T-cell proliferation in colorectal cancer. Cancer Res 73: 539-549, 2013.

20. Sessa C, Guibal A, Del Conte G and Rüegg C: Biomarkers of angiogenesis for the development of antiangiogenic therapies in oncology: Tools or decorations? Nat Clin Pract Oncol 5: 378-391, 2008.

21. Higdon JV, Delage B, Williams DE and Dashwood RH: Cruciferous vegetables and human cancer risk: epidemiologic evidence and mechanistic basis. Pharmacol Res 55: 224-236, 2007.

22. Tse G and Eslick GD: Cruciferous vegetables and risk of colorectal neoplasms: A systematic review and meta-analysis. Nutr Cancer 66: 128-139, 2014.

23. Yao H, Wang $\mathrm{H}$, Zhang $\mathrm{Z}$, Jiang $\mathrm{BH}$, Luo J and Shi $\mathrm{X}$ : Sulforaphane inhibited expression of hypoxia-inducible factorlalpha in human tongue squamous cancer cells and prostate cancer cells. Int J Cancer 123: 1255-1261, 2008.

24. Shan Y, Sun C, Zhao X, Wu K, Cassidy A and Bao Y: Effect of sulforaphane on cell growth, $\mathrm{G}_{0} / \mathrm{G}_{1}$ phase cell progression and apoptosis in human bladder cancer T24 cells. Int J Oncol 29: $883-888,2006$

25. Shan Y, Wu K, Wang W, Wang S, Lin N, Zhao R, Cassidy A and Bao Y: Sulforaphane down-regulates COX-2 expression by activating p38 and inhibiting NF-kappaB-DNA-binding activity in human bladder T24 cells. Int J Oncol 34: 1129-1134, 2009.

26. Wang Y, Dacosta C, Wang W, Zhou Z, Liu M and Bao Y: Synergy between sulforaphane and selenium in protection against oxidative damage in colonic CCD841 cells. Nutr Res 35: 610-617, 2015. 
27. Asakage M, Tsuno NH, Kitayama J, Tsuchiya T, Yoneyama S, Yamada J, Okaji Y, Kaisaki S, Osada T, Takahashi K, et al: Sulforaphane induces inhibition of human umbilical vein endothelial cells proliferation by apoptosis. Angiogenesis 9: 83-91, 2006.

28. Nishikawa T, Tsuno NH, Tsuchiya T, Yoneyama S, Yamada J, Shuno Y, Okaji Y, Tanaka J, Kitayama J, Takahashi K, et al: Sulforaphane stimulates activation of proapoptotic protein bax leading to apoptosis of endothelial progenitor cells. Ann Surg Oncol 16: 534-543, 2009.

29. Nishikawa T, Tsuno NH, Okaji Y, Sunami E, Shuno Y, Sasaki K, Hongo K, Kaneko M, Hiyoshi M, Kawai K, et al: The inhibition of autophagy potentiates anti-angiogenic effects of sulforaphane by inducing apoptosis. Angiogenesis 13: 227-238, 2010.

30. Jackson SJ, Singletary KW and Venema RC: Sulforaphane suppresses angiogenesis and disrupts endothelial mitotic progression and microtubule polymerization. Vascul Pharmacol 46: 77-84, 2007

31. Bertl E, Bartsch $\mathrm{H}$ and Gerhäuser C: Inhibition of angiogenesis and endothelial cell functions are novel sulforaphane-mediated mechanisms in chemoprevention. Mol Cancer Ther 5: 575-585, 2006.

32. Davis R, Singh KP, Kurzrock R and Shankar S: Sulforaphane inhibits angiogenesis through activation of FOXO transcription factors. Oncol Rep 22: 1473-1478, 2009

33. Barrera LN, Cassidy A, Wang W, Wei T, Belshaw NJ, Johnson IT, Brigelius-Flohé R and Bao Y: TrxR1 and GPx2 are potently induced by isothiocyanates and selenium, and mutually cooperate to protect Caco-2 cells against free radical-mediated cell death. Biochim Biophys Acta 1823: 1914-1924, 2012.

34. Whayne TF Jr, Parinandi N and Maulik N: Thioredoxins in cardiovascular disease. Can J Physiol Pharmacol 93: 903-911, 2015.

35. Cooley LS, Handsley MM, Zhou Z, Lafleur MA, Pennington CJ, Thompson EW, Pöschl E and Edwards DR: Reversible transdifferentiation of blood vascular endothelial cells to a lymphatic-like phenotype in vitro. J Cell Sci 123: 3808-3816, 2010.

36. Brachvogel B, Pausch F, Farlie P, Gaipl U, Etich J, Zhou Z, Cameron T, von der Mark K, Bateman JF and Pöschl E: Isolated Anxa $5^{+} / \mathrm{Sca}-1^{+}$perivascular cells from mouse meningeal vasculature retain their perivascular phenotype in vitro and in vivo. Exp Cell Res 313: 2730-2743, 2007.

37. Zhou Z, Pausch F, Schlötzer-Schrehardt U, Brachvogel B and Pöschl E: Induction of initial steps of angiogenic differentiation and maturation of endothelial cells by pericytes in vitro and the role of collagen IV. Histochem Cell Biol 145: 511-525, 2016.

38. Bader BL, Rayburn H, Crowley D and Hynes RO: Extensive vasculogenesis, angiogenesis, and organogenesis precede lethality in mice lacking all alpha v integrins. Cell 95: 507-519, 1998.

39. Streicher KL, Sylte MJ, Johnson SE and Sordillo LM: Thioredoxin reductase regulates angiogenesis by increasing endothelial cell-derived vascular endothelial growth factor. Nutr Cancer 50: 221-231, 2004.

40. Griffith LG and Swartz MA: Capturing complex 3D tissue physiology in vitro. Nat Rev Mol Cell Biol 7: 211-224, 2006.

41. Fang C, Man YG, Cuttitta F, Stetler-Stevenson W, Salomon D, Mazar A, Kulesza P, Rosen S, Avital I, Stojadinovic A, et al: Novel phenotypic fluorescent three-dimensional co-culture platforms for recapitulating tumor in vivo progression and for personalized therapy. J Cancer 4: 755-763, 2013.
42. Nascarella MA, Stanek EJ III, Hoffmann GR and Calabrese EJ: Quantification of hormesis in anticancer-agent dose-responses. Dose Response 7: 160-171, 2009.

43. Ushio-Fukai M and Nakamura Y: Reactive oxygen species and angiogenesis: NADPH oxidase as target for cancer therapy. Cancer Lett 266: 37-52, 2008

44. Pagès G and Pouysségur J: Transcriptional regulation of the vascular endothelial growth factor gene - a concert of activating factors. Cardiovasc Res 65: 564-573, 2005.

45. Beaver LM, Buchanan A, Sokolowski EI, Riscoe AN, Wong CP, Chang JH, Löhr CV, Williams DE, Dashwood RH and Ho E: Transcriptome analysis reveals a dynamic and differential transcriptional response to sulforaphane in normal and prostate cancer cells and suggests a role for Sp1 in chemoprevention. Mol Nutr Food Res 58: 2001-2013, 2014.

46. Ji W, Yang M, Praggastis A, Li Y, Zhou HJ, He Y, Ghazvinian R, Cincotta DJ, Rice KP and Min W: Carbamoylating activity associated with the activation of the antitumor agent laromustine inhibits angiogenesis by inducing ASK1-dependent endothelial cell death. PLoS One 9: e103224, 2014.

47. Lincoln DT, Ali Emadi EM, Tonissen KF and Clarke FM: The thioredoxin-thioredoxin reductase system: Over-expression in human cancer. Anticancer Res 23: 2425-2433, 2003.

48. Li D, Wang W, Shan Y, Barrera LN, Howie AF, Beckett GJ, Wu K and Bao Y: Synergy between sulforaphane and selenium in the up-regulation of thioredoxin reductase and protection against hydrogen peroxide-induced cell death in human hepatocytes. Food Chem 133: 300-307, 2012.

49. Kim YW and Byzova TV: Oxidative stress in angiogenesis and vascular disease. Blood 123: 625-631, 2014

50. Bir SC, Shen X, Kavanagh TJ, Kevil CG and Pattillo CB: Control of angiogenesis dictated by picomolar superoxide levels. Free Radic Biol Med 63: 135-142, 2013.

51. García-Quintans N, Sánchez-Ramos C, Prieto I, Tierrez A, Arza E, Alfranca A, Redondo JM and Monsalve M: Oxidative stress induces loss of pericyte coverage and vascular instability in PGC-1 $\alpha$-deficient mice. Angiogenesis 19: 217-228, 2016.

52. Li WW, Li VW, Hutnik M and Chiou AS: Tumor angiogenesis as a target for dietary cancer prevention. J Oncol 2012: 879623, 2012.

53. Radomska-Leśniewska DM, Hevelke A, Skopiński P, Bałan B, Jóźwiak J, Rokicki D, Skopińska-Różewska E and Białoszewska A: Reactive oxygen species and synthetic antioxidants as angiogenesis modulators: Clinical implications. Pharmacol Rep 68: 462-471, 2016.

54. Campbell L, Howie F, Arthur JR, Nicol F and Beckett G: Selenium and sulforaphane modify the expression of selenoenzymes in the human endothelial cell line EAhy926 and protect cells from oxidative damage. Nutrition 23: 138-144, 2007.

55. Shan Y, Zhao R, Geng W, Lin N, Wang X, Du X and Wang S: Protective effect of sulforaphane on human vascular endothelial cells against lipopolysaccharide-induced inflammatory damage. Cardiovasc Toxicol 10: 139-145, 2010 